\title{
Primary Retroperitoneal Cystic Neoplasm- Case Report
}

\author{
Abinaya Lenin¹, Krishna Govindan²
}

${ }^{1}$ Department of Pathology, Government Medical College, Thiruvananthapuram, Kerala, India.

2Department of Pathology, Government Medical College, Thiruvananthapuram, Kerala, India.

\section{INTRODUCTION}

Most retroperitoneal tumours arise from kidneys, adrenals, pancreas. In primary retroperitoneal tumours, lymphomas and mesenchymal neoplasms are more common. Cystic neoplasm of retroperitoneum is uncommon. Malignant tumours are seen more often than benign lesions. Metastatic disease in retroperitoneum is usually recurrence of a urological or gynaecological tumours. Primary retroperitoneal tumours are rare tumours and these tumours account for $0.1 \%-0.2 \%$ of all malignancies. ${ }^{1}$ In our institution we had an interesting cystic neoplasm in the retroperitoneum.

\section{PRESENTATION OF CASE}

A 50-year-old female patient presented with, abdominal distension, loss of weight, and fatigue from past 5 years.

\section{CT Scan Abdomen}

Roughly oval cystic lesion mean. 17 × 10 × $8.5 \mathrm{cms}$ noted in left pericolic region. Small mural nodules seen, largest seen in the upper pole. Wall thickness ranges from 2-7 $\mathrm{mm}$. Right ovary shows thin walled unilocular benign cyst. Left ovary not well visualized separately. (Fig $1 \& 2$ ).

Serum markers were elevated. (S. CEA- 22.18, S. CA19-9 >2040, CA125 - 78.2). Aspirate of cyst fluid showed high CEA values (CA19-9 -250.70). Colonoscopy \& biopsy were within normal limits.
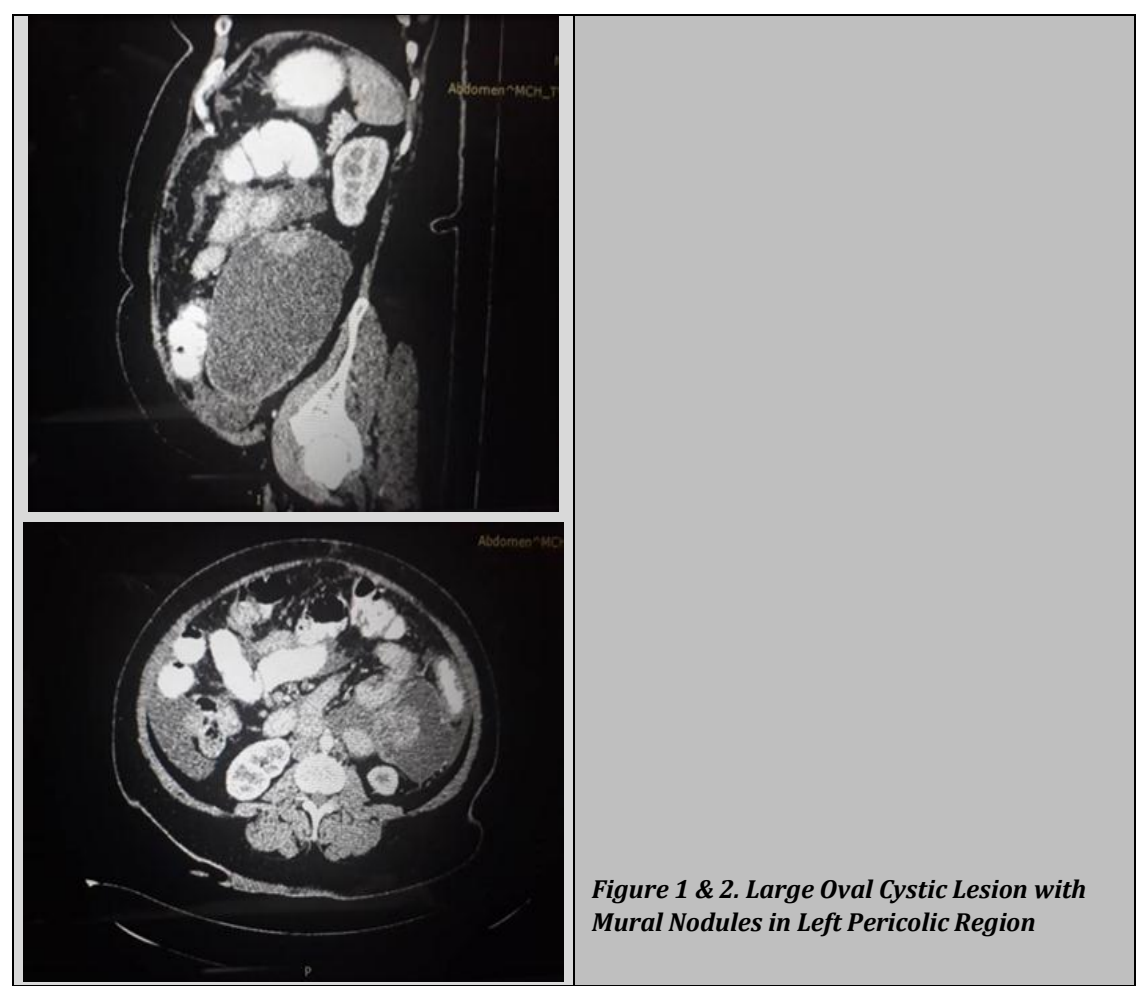

Corresponding Author:

Dr. Krishna Govindan,

Professor and HOD,

Department of Pathology,

Government Medical College,

Thiruvananthapuram, Kerala, India.

E-mail: drkrishnagovindan@gmail.com

DOI: $10.14260 / \mathrm{jemds} / 2020 / 320$

Financial or Other Competing Interests: None.

How to Cite This Article:

Lenin A, Govindan K. Primary retroperitoneal cystic neoplasm- case report. J. Evolution Med. Dent. Sci. 2020;9(17):1467-1470, 10.14260/jemds/2020/320

Submission 29-02-2020, Peer Review 11-04-2020, Acceptance 18-04-2020, Published 27-04-2020.

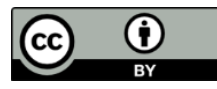




\section{FNAC from Mural Nodule}

Pap stained moderately cellular smear shows atypical cells seen in clusters and sheets. Individual cells shows high N: C ratio, irregular nuclear membrane, vesicular nucleus with conspicuous nucleoli. Background shows inflammatory cells (Fig. 3 \& 4). Cell block shows cells are arranged in glandular pattern. Individual cells are having scanty cytoplasm, pleomorphic vesicular nucleus. (Fig. 5)

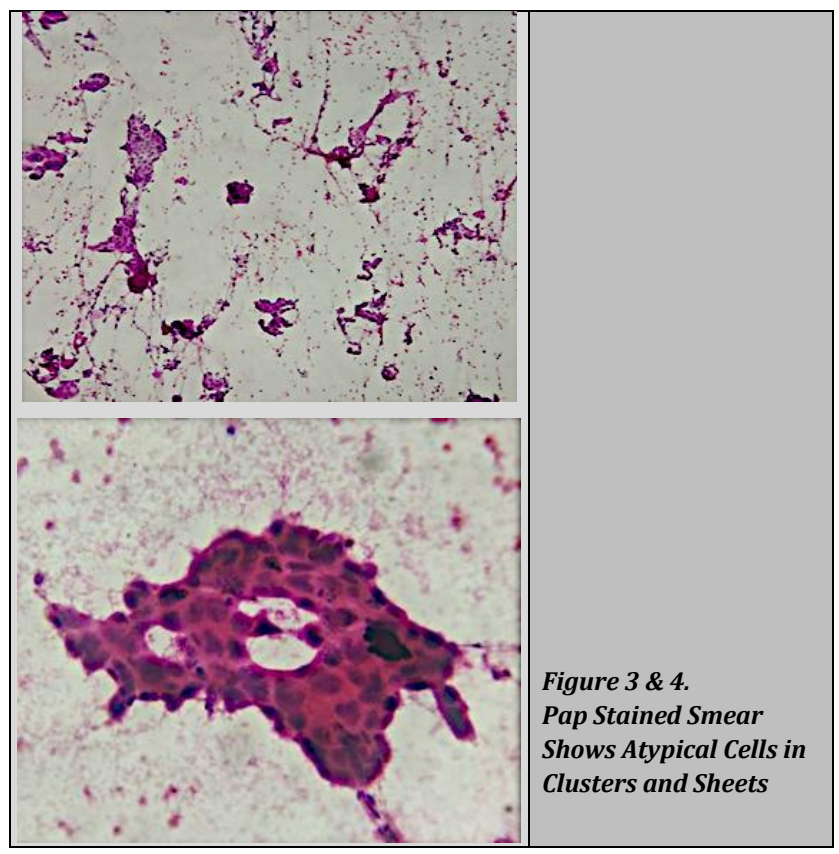

Immunocytochemistry: CK7, CK19 were positive. Cytology Diagnosis: suggestive of adenocarcinoma, favouring origin from pancreas, breast.

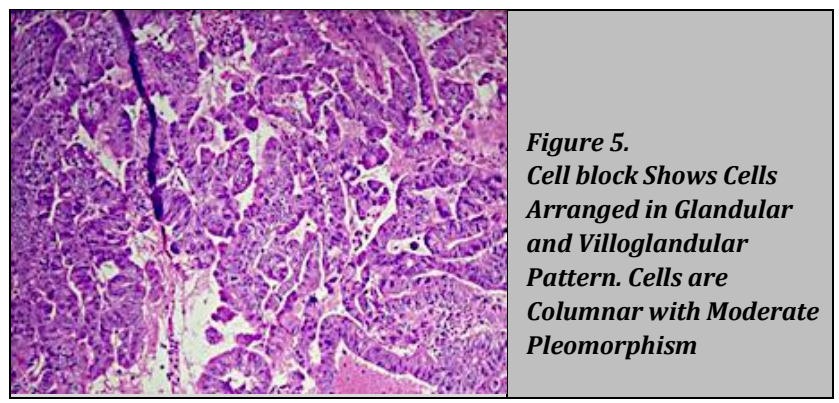

\section{Whole Body PET Scan}

Mass in left side of abdomen in left lumbar and iliac fossa with FDG uptake in soft tissue nodular lesion along its periphery, left ovary not separately visualized, uterus and right ovary appears unremarkable.

Patient underwent TAH with BSO, and excision of retroperitoneal mass.

\section{Intraoperative Finding}

Tumour was unrelated to any organ.

\section{Macroscopy}

Collapsed cystic mass weighing 305 gm, measuring. 13 x 11 x $3 \mathrm{cms}$. Surface shows attached fibro fatty tissue and congested vessels. Cut section let out whitish fluid, cutting open identified uniloculated cyst with wall thickend. Solid area identified measuring $4.5 \times 3 \mathrm{~cm}$ cut section which is grey white and granular. Multiple papillary excrescences identified, largest over an area measuring $1.5 \times 1.5 \mathrm{~cm}$.

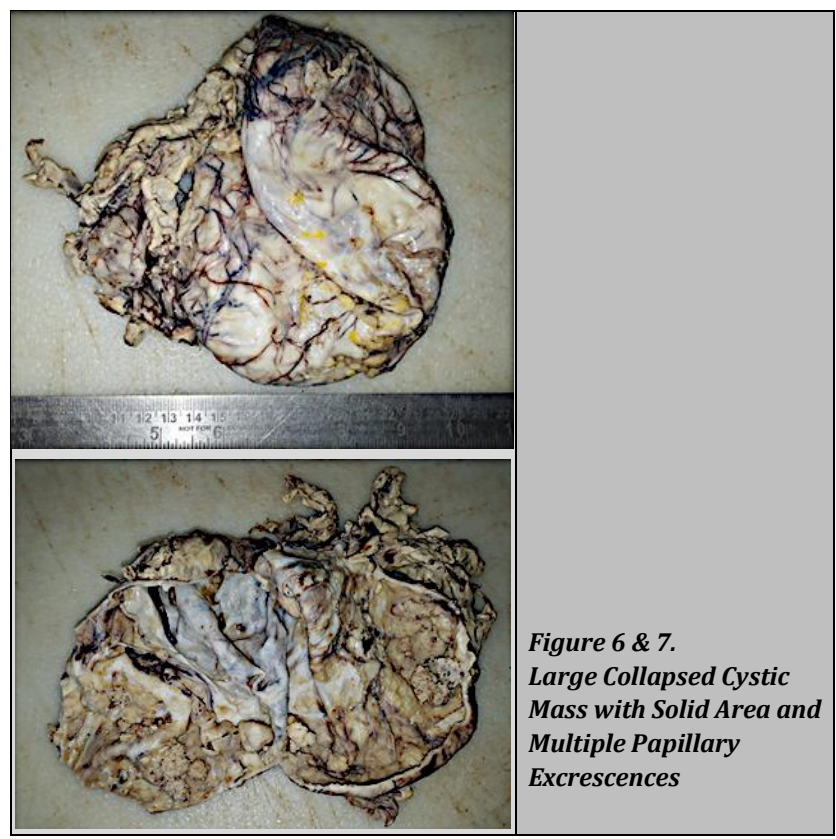

\section{Uterus}

Endometrial cavity was normal, myometrium showed a single fibroid measuring $2.5 \times 2.5 \times 2 \mathrm{cms}$. Cervix, both tubes and ovaries were normal.

\section{Microscopy}

Section from retroperitoneal mass showed neoplasm composed of cells arranged in glandular and villoglandular pattern. Individual cells are columnar with moderate amount of Eosinophilic cytoplasm pleomorphic nucleus with coarse clumped chromatin and prominent nucleoli. Nuclear crowding overlapping seen. Atypical mitosis, areas of necrosis noted. Focal mucinous area noted. (Fig. 8, 9, 10)

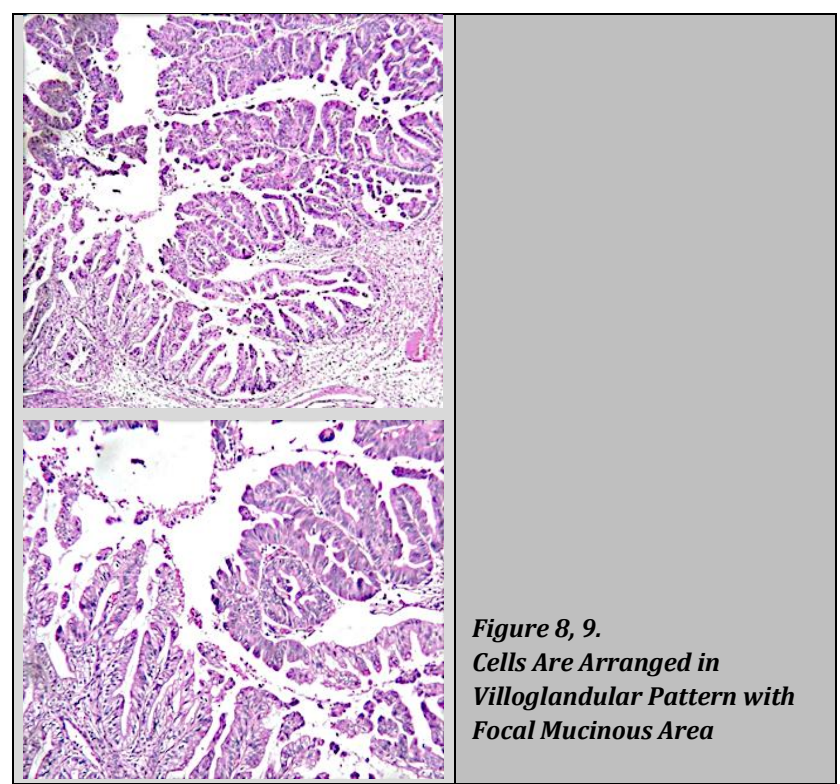




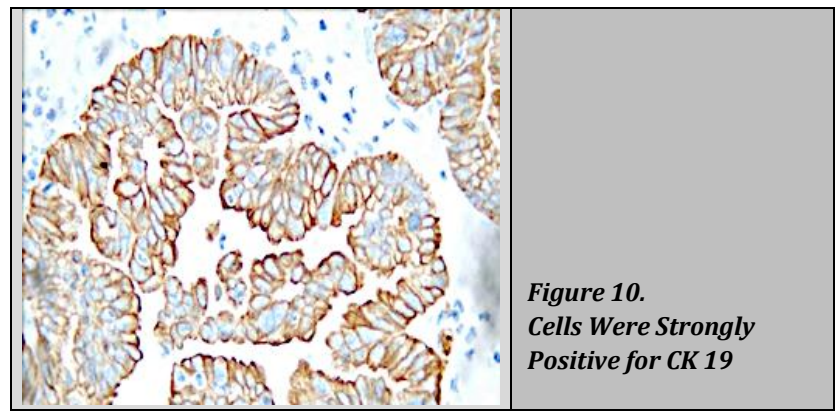

IHC

CK 7 \& CK 19 exhibited strong positivity (Fig. 11) and CK 20, p53, WT1 were negative.

Uterus showed proliferative endometrium, leiomyoma, chronic cervicitis. Both ovaries corpus albicans, corpus luteum, both tubes were normal.

\section{Diagnosis}

We made a diagnosis of Mucinous cystic neoplasm with an associated invasive carcinoma for retroperitoneal tumour.

\section{DISCUSSION}

Primary retroperitoneal tumours are tumours that arise in retroperitoneum independently of any organ. They represent a multiplicity of cell types arising from ectoderm, mesoderm or mixed cell types and residues of embryonic urogenital body ${ }^{1,2}$. Such tumours are rare and $70 \%$ of them are malignant and these tumours accounting for $0.1 \%-0.2 \%$ of all malignancies. ${ }^{3}$ Symptoms are usually not present until later in the disease. ${ }^{4}$

Primary retroperitoneal masses can be divided into solid and cystic. Solid neoplasms can be split into four groups 1 . Mesodermal neoplasms 2. Neurogenic tumours 3. Germ cell, sex cord, stromal tumours, 4. Lymphoid and hematologic neoplasms.5,6 Retroperitoneal cysts are infrequent, these tumours rarely producing symptoms, usually symptoms being related to cyst location and size and their complications.

Primary Serous or mucinous cystadenocarcinoma is rare epithelial retroperitoneal tumour and the exact origin of these tumours remain unclear. Many theories have been postulated and one of the most accepted of these that of ectopic or supernumerary ovarian tissue. ${ }^{6}$ But it is noteworthy that ovarian tissue or remnants of normal ovarian tissue were not found in any reported cases including ours. ${ }^{7,8}$ People argue against this theory since few cases in males have been reported previously. Another theory is celomic metaplasia in which some clusters of celomic epithelial cells are deposited in the retroperitoneal area, developing an inclusion cyst.

These cells eventually experience metaplastic changes resulting in mucinous tumours that finally have cytologic changes, thus gaining the malignant phenotype. ${ }^{8,9}$, Some authors have proposed that the peritoneal epithelium possesses the potential for Müllerian differentiation, as do all epithelial ovarian tumours. ${ }^{8,10}$ This concept has been supported by some authors based on immunohistochemical and electron-microscopy evaluation of the tumours.8,11
Another is the possibility of mucinous tissue overgrowing other components of a teratoma 8,12

Primary retroperitoneal mucinous neoplasm is categorized into 3 types, benign mucinous cystadenoma, borderline mucinous cystadenoma, malignant mucinous cystadenocarcinoma. ${ }^{8}$ In our case the initial differential diagnosis considered were metastatic adenocarcinoma from ovary, intestine, pancreas. But by intra operative findings the tumour was found to be unrelated to any organ and also with the help of imaging and PET scan there was no primary other than the mass. We have applied a panel of IHC to rule out possible origin. Out of all the markers CK7, CK19 found to be strongly positive for tumour cells and negative for CK20 with strong positive for these markers we can presume that this tumour could possibly be arising from celomic metaplasia.

Surgery is the mainstay of treatment for these tumours which was mentioned by De Leon DC et al and he also mentioned adjuvant chemotherapy is not a standard treatment and is beneficial only where tumour has been ruptured during surgery, or invasion to adjacent organs.

\section{CONCLUSIONS}

Retroperitoneal masses can appear from different tissues and are a heterogeneous group, including some rare neoplasms. Histopathology, IHC, imaging techniques and other diagnostic exams are valuable in the evaluation of retroperitoneal masses, particularly in staging as well as in nearby invasion. Evaluation of cystic mass in retroperitoneum should be done only with detailed information from radiology findings, and per operative findings.

\section{REFERENCES}

[1] Pai MR, Nail R, Raghuveer CV. Primary retroperitoneal tumours a 25 year study. Indian J Med Sci 1995;49(6):139-41.

[2] Scanlan DB. Primary retroperitoneal tumours. The Journal of Urology 1959;81(6):740-5.

[3] Bradley MJ, Cosgrove DO. The abdominal wall, peritoneum and retroperitoneum. Clinical Ultrasound 2011.

[4] Caliskan M, Evren I, Acar A, et al. Analysis of cases with primary retroperitoneal tumours. Bakirkoy Tip Dergisi 2019;15:38-40.

[5] Rajiah P, Sinha R, Cuevas C, et al. Imaging of uncommon retroperitoneal masses. Radiographics 2011;31(4):94976.

[6] Cherciu A, lorga L, Anghel R, et al. Primary retroperitoneal tumours - a brief classification and differential diagnosis. Romanian Journal of Military Medicine 2019;122:9-15.

[7] Kehagias DT, Karvounis EE, Fotopoulos A, et al. Retroperitoneal mucinous cystadenoma. Eur J Obstet Gynecol Reprod Biol 1999;82(2):213-5.

[8] De Leon DC, Perez-Montiel D, Chanona-Vilchis J, et al. Primary retroperitoneal mucinous cyastadenocarcinoma: report of two cases. World Journal of Surgical Oncology 2007;5(1):5. 
[9] Matsubara M, Shiozawa T, Tachibana R, et al. Primary retroperitoneal mucinous cystadenoma of borderline malignancy: a case report and review of the literature. Int J Gynecol Pathol 2005;24(3):218-23.

[10] Gotoh K, Konaga E, Arata A, et al. A case of primary retroperitoneal mucinous cystadenocarcinoma. Acta Med Okayama 1992;46(1):49-52.
[11] Tangjitgamol S, Manusirivithaya S, Sheanakul C, et al. Retroperitoneal mucinous cystadenocarcinoma: a case report and review of literature. Int J Gynecol Cancer 2002;12(4):403-8.

[12] Danyan D, Abu-Abeid S, Klausner JM, et al. Primary retroperitoneal mucinous cystic neoplasm: Authors' experience and review of the literature. American Journal of Clinical Oncology 2016;39(5):433-40. 